\title{
The morphometric characters variability analysis of Tulipa uniflora (Liliaceae) in the Angara Region (Irkutsk Oblast, Russia)
}

\author{
Olga Chernysheva ${ }^{1, *}$, Yuriy Bukin ${ }^{2}$, and Denis Krivenko ${ }^{1,3}$ \\ ${ }^{1}$ Siberian Institute of Plant Physiology and Biochemistry SB RAS, 664033 Irkutsk, Russia \\ ${ }^{2}$ Limnological Institute SB RAS, 664033 Irkutsk, Russia \\ ${ }^{3}$ Federal State Budgetary Institution Western Baikal Protected Areas, 664050 Irkutsk, Russia
}

\begin{abstract}
The intra- and interpopulation variability of six populations of Tulipa uniflora (L.) Besser ex Baker at the northern limit of distribution in the Angara steppes over 12 morphometric parameters was studied by the principal components method and single-factor analysis of variance. It is established that the vectors characterizing the gradients of the change in the morphometric parameters are divided into two groups: vegetative and generative, which are among themselves in direct dependence. Based on the single-factor analysis of variance results for all morphometric parameters, a significant difference is observed between populations of $T$. uniflora in the Angara Region. On the one hand, this is a consequence of anthropogenic impact on the population, and on the other - the relic nature of the species.
\end{abstract}

\section{Introduction}

Wild tulips are famous ornamental plants. They are the ancestors of cultural species and an inexhaustible source for breeding new varieties. They have an invaluable advantage over cultural plants: an exceptionally diverse color of the perianth, they are immune to the variegation virus [1]. Natural types of tulips need a wider introduction to culture, including gardening in the territory of Siberia. The study of the morphometric characters variability of the species of the genus Tulipa L. is of great importance in assessing the state of natural populations of species. The survey of as many tulip sites as possible allows revealing key indicating morphometric characters and ecological and biological optimums typical for each species. The presented study is aimed at the analysis of the variability of T. uniflora morphometric characters, including the analysis under the influence of anthropogenic impact on populations at the northern border of growth in the steppes of the Angara Region.

\section{Materials and Methods}

\footnotetext{
* Corresponding author: helga8408@mail.ru
} 
T. uniflora is mainly a Central Asian steppe species. In South Siberia the species is registered in the Central Altai, Tuva, Ubsunur, Khakass, Angara Region and Daurian steppes $[2,3]$. At the northern border of growth $T$. uniflora belongs to the category of rare and endangered plant species. The species is a tertiary relic of the Miocene-Pliocene flora. The life cycle of the species is in disharmony with the existing natural conditions. $T$. uniflora blossoms in late April-early May. Early flowering is a necessary phenomenon in Central Asia where it is determined by the aridity of summer. Since in South Siberia drought usually occurs in May-June and precipitation falls in July-August, the mentioned features of the life cycle are explained only by historical causes.

The studies were carried out in 2017 in Ekhirit-Bulagatsky, Ust-Udinsky, Osinsky, Bokhansky Districts of the Irkutsk Oblast (Table 1). In each population up to 12 morphometric characters were measured in 15-25 random specimens which were in a generative ontogenetic state.

Table 1. The studied populations of Tulipa uniflora in the Irkutsk Oblast.

\begin{tabular}{|c|c|c|}
\hline Location - Symbol designation & $\mathrm{N} / \mathrm{E}$ & $\begin{array}{c}\text { Stage of grazing } \\
\text { digression [8] }\end{array}$ \\
\hline Bokhansky District, Khandagai $-H$ & $\begin{array}{l}53^{\circ} 11^{\prime} 12.5^{\prime \prime} / \\
103^{\circ} 37^{\prime} 01.7^{\prime \prime}\end{array}$ & $3-4$ \\
\hline Bokhansky District, Bohan $-B$ & $\begin{array}{l}53^{\circ} 09^{\prime} 40.8^{\prime \prime} / \\
103^{\circ} 48^{\prime} 02.9^{\prime \prime}\end{array}$ & 9 \\
\hline Osinsky District, Lenino $-L$ & $\begin{array}{l}53^{\circ} 41^{\prime} 26.5^{\prime \prime} / \\
103^{\circ} 45^{\prime} 23.8^{\prime \prime}\end{array}$ & $6-7$ \\
\hline Osinsky District, Obusa $-O$ & $\begin{array}{l}53^{\circ} 43^{\prime} 18.2^{\prime \prime} / \\
103^{\circ} 49^{\prime} 15.0^{\prime \prime}\end{array}$ & 5 \\
\hline Ust-Udinsky District, Igzhey $-I$ & $\begin{array}{l}54^{\circ} 03^{\prime} 25.7^{\prime \prime} / \\
103^{\circ} 62^{\prime} 25.6^{\prime \prime}\end{array}$ & $6-7$ \\
\hline Ekhirit-Bulagatsky District, Gahany - G & $\begin{array}{l}53^{\circ} 02^{\prime} 05.1^{\prime \prime} / \\
104^{\circ} 52^{\prime} 46.0^{\prime \prime}\end{array}$ & $3-4$ \\
\hline
\end{tabular}

Due to the fact that T. uniflora has a short blossoming period, it was not possible to measure some morphometric characters of the flower in the populations $B, H, I, L$; therefore the original data table had missing data. The restoration of the missing data was carried out using the multidimensional linear regression according to the recommendations of W.R. Myers [4] and K.J. Lee \& J.B. Carlin [5].

Before the statistical analysis the array of morphometric data was normalized with the help of a standard metric with the purpose to bring all the considered morphometric parameters to a single scale of measurement and to balance their contribution to the variability of the data array. To analyze and visualize the distribution of the specimens under study for a set of morphometric characters, one of the methods of multidimensional statistics (the method of principal components) was used [6].

To assess the measure of discrepancy in the morphometric characters in the populations studied, we used the single-factor analysis of variance with the Fisher criterion $(\alpha=0.05)$ [7]. The measure of discrepancy $(\mathrm{H})$ between populations according to the test feature was calculated by the formula: $\mathrm{H}=1-1 / \mathrm{F}$, where $\mathrm{F}$ is the value of the Fisher criterion. $\mathrm{H}$ takes a value from 0 to 1 ; the closer it is to 1 , the more the populations differ. The nature and extent of anthropogenic impact in the populations were estimated by the pasture degradation scale of L.G. Ramensky and others [8]. All the statistical calculations and the construction of the diagram were carried out in a shareware statistical environment for programming purposes $\mathrm{R}$. 


\section{Results}

The scatter diagram characterizing the specimens under study in the space of the first two principal components is shown in the figure. Point clouds which combine the specimens in the populations have a different overlapping. The greater the overlapping of clouds is, the more similar the populations are among themselves according to the morphometric characters under analysis. The most similar populations are $\boldsymbol{B}, \boldsymbol{G}, \boldsymbol{H}, \boldsymbol{L}$ and $\boldsymbol{O}$. The specimens from the population $\boldsymbol{I}$ are the most different from the specimens of the other populations. The specimens from the populations $\boldsymbol{G}$ and $\boldsymbol{I}$ differ significantly.

The vectors characterizing the gradients of the change in the morphometric characters on the scatter diagram (Fig.) are divided into two groups. The co-directional vectors of the parameters of the length and width of the prophyll and the secondary leaf, the stamen height and the generative shoot height are associated in the first group. The vectors of the parameters of the length and width of the inner and outer perianth and the pistil height are associated in the second group. These parameters are related to each other by the direct dependence in both groups.

With an increase in the value of one of the analyzed morphometric characters, the other parameters also increase as a rule. The two groups of vectors are almost perpendicular to each other. That indicates that there is no correlation between these groups of features.

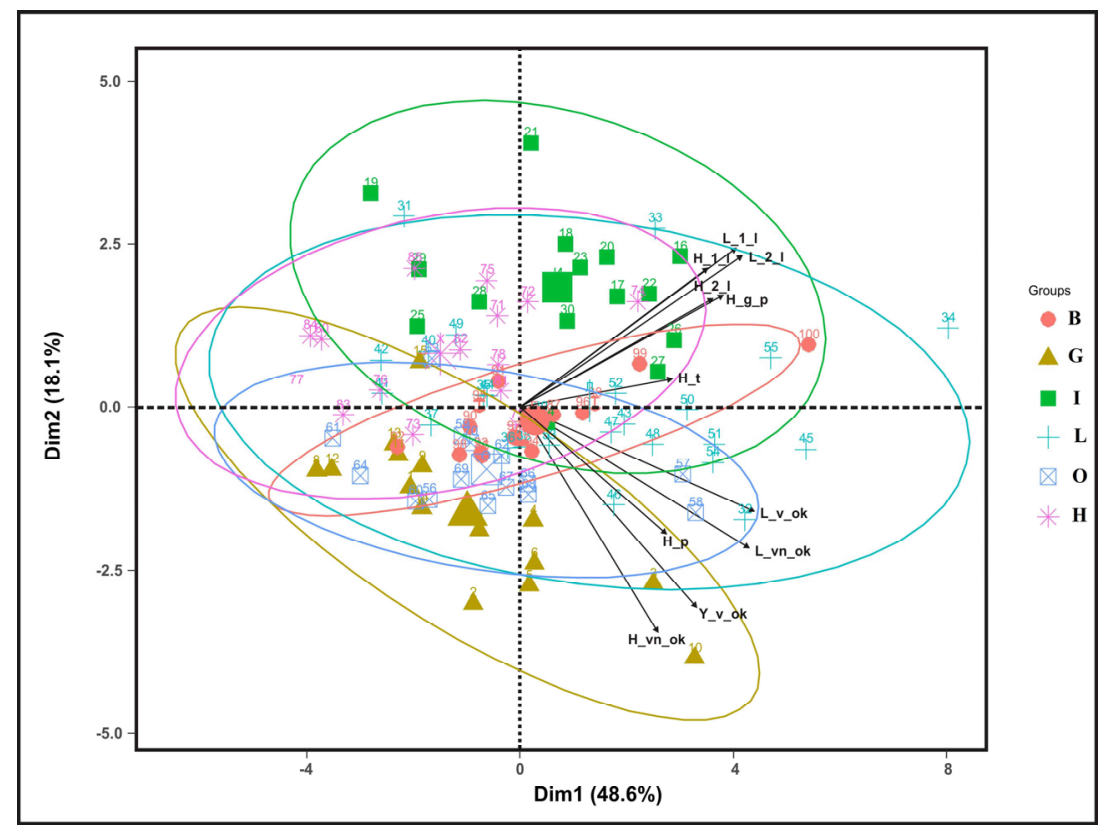

Fig. Scatter diagram characterizing the studied specimens of Tulipa uniflora in the space of the first two principal components. Ellipses outline the point clouds, the concentration of specimens from the certain populations. The vectors show the gradient direction of the change in the morphometric characters under study. The designation of populations is given in Table 1, the designation of the features is given in Table 2 .

The results of the single-factor analysis of variance are shown in Table 2. There is a significant difference between the populations for all the features. The greatest difference is observed in the stamen height $(\mathrm{H}=0.907)$. Three features are least distinguished: the length of the inner and outer perianth and the pistil height $(\mathrm{H}<0.7)$. For the other features the value of $\mathrm{H}$ exceeds 0.8 ; that indicates a fairly significant level of difference between the populations. 
Table 3. Results by a single-factor variance analysis of Tulipa uniflora.

\begin{tabular}{|c|c|c|c|}
\hline $\begin{array}{c}\text { Name of morphometric character - Symbol } \\
\text { designation }\end{array}$ & F & H & P_value \\
\hline Height of generative shoot - H_g_p & 7.290 & 0.862 & 0.000 \\
\hline Length of first leaf - L_1_1 & 9.629 & 0.896 & 0.000 \\
\hline Width of first leaf - H_1_l & 7.167 & 0.860 & 0.000 \\
\hline Length of second leaf - L_2_l & 9.299 & 0.890 & 0.000 \\
\hline Width of second leaf - H_2_l & 6.481 & 0.845 & 0.000 \\
\hline Length of outer perianth - L_v_ok & 3.263 & 0.693 & 0.009 \\
\hline Width of outer perianth - Y_v_ok & 9.862 & 0.898 & 0.000 \\
\hline Length of inner perianth - L_vn_ok & 3.434 & 0.708 & 0.006 \\
\hline Width of inner perianth - H_vn_ok & 9.103 & 0.890 & 0.000 \\
\hline Height of stamen - H_t & 10.800 & 0.907 & 0.000 \\
\hline Height of pestle - H_p & 3.019 & 0.668 & 0.014 \\
\hline
\end{tabular}

\section{Discussion}

Morphological differentiation of the specimens of the population $I$ from the specimens of the populations $B, G, H, L$ and $O$ can be explained by the geographic remoteness of the first from the others by $60-160 \mathrm{~km}$ and by the significant anthropogenic impact on it (Table 1). The habitat of $T$. uniflora of the population $I$ is confined to the gentle slope $\left(<30^{\circ}\right)$; that is a convenient place for grazing cattle and small ruminants; the proximity of the ferry and motorway makes the slope accessible to people. Soil erosion was noted here as a consequence of the anthropogenic impact. The specimens from the populations $I$ and $G$ differ significantly according to their morphometric characters. This is due to the remoteness of the populations from each other by $160 \mathrm{~km}$, the natural isolation of the population $G$, including the populations $B, H$, L and $O$, the Kuda River and forestlands. The latter circumstance is an obstacle for cross-pollination between the specimens of the population $G$ with the other populations. It should be noted that the habitat of the population $G$, unlike the population $I$, is undisturbed (Table 1 ) despite the proximity of the locality. However, the slope where T. uniflora dwells is much steeper $\left(\sim 50^{\circ}\right)$ which makes it difficult to graze livestock.

To dividing vectors into generative and vegetative groups is consistent with the data obtained by L.V. Mukhametshina and others [9] for the South Ural populations $T$. biebersteiniana Schult. \& Schult.f., T. patens C.Agardh ex Schult. \& Schult.f. and T. riparia Knjaz., Kulikov \& E.G.Philippov.

For the T. uniflora populations in the Angara Region the feature of the stamen height is knocked out from the general direction of the vectors of generative features. According to the results of the single-factor analysis of variance according to the Fisher criterion, the greatest difference among the populations is observed on this feature (Table 2). This is probably related to the fact that in some populations the phasing out of the stage of tulip blossoming was observed.

The low variability of the morphometric characters of the generative sphere in comparison with the features of the vegetative sphere in the populations is quite natural, since the flower has an exceptional role as a special morphological structure associated with the fact that it completely combines all the processes of agamic and sexual reproduction. Excluding microclimatic and relief-forming factors, the mentioned features of the variability of the morphometric characters in the specimens of $T$. uniflora from the populations of the Angara Region can also be explained by historical causes, namely the 
prolonged genetic isolation of the peripherical populations from the main part of the area of species.

The reported study was funded by RFBR according to the research project № 18-34-00551.

\section{References}

1. Z. P. Bochantseva, Tulips. Morphology, cytology and biology. (Publishing House of the Academy of Sciences of the Uzbek SSR, Tashkent, 1962)

2. N.V. Vlasova, Tulipa L. Flora Sibiri, 4 (Nauka, Novosibirsk, 1987)

3. G.A. Peshkova, Florogeneticheskii analiz stepnoi flory gor Yuzhnoi Sibiri (Science Publishers, Inc., Novosibirsk, 2001)

4. W.R. Myers, Drug. Inf. J. 34, 525-533 (2000)

5. K.J. Lee, J.B. Carlin, Am. J. Epidemiol. 171, 624-632 (2010)

6. S.A. Aivazyan, V.M. Buchstaber, E. S. Enyukov, et al., Prikladnaya statistika. Klassifikatsiya i snizheniye razmernosti (Finance and Statistics, Moscow, 1989)

7. J.M. Chambers, A. Freeny, R.M. Heiberger, Analysis of variance; designed experiments (Statistical Models in S, Cole, 1992)

8. L.G. Ramenskii, I.A. Tsatsenkin, O.N. Chizhikov, et al., Ekologicheskaya otsenka kormovykh ugodii po rastitelnomu pokrovu (Sel'khozgiz, Moscow, 1956)

9. L.V. Mukhameditdishina, E.Z. Mullabaeva, M.M. Ishmuratova, Izvestiya Samarskogo nauchnogo tsentra RAN 16, 1650-1653 (2014) 